\title{
Reciclagem de éter-aminas, utilizadas na flotação de minério de ferro, por meio da adsorção
}

\author{
Recycling of éther-amines, used in iron ore flotation, by adsorption

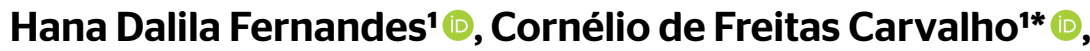 \\ Caio Cesar Pereira de Paula' ${ }^{(\mathbb{D}}$, Luana Silva de Azevedo' ${ }^{(\mathbb{D}}$, Sabrina Mayra Dias Gonçalves $^{1}(\mathbb{D}$
}

\begin{abstract}
RESUMO
O presente trabalho teve por objetivo verificar uma possível rota de reciclagem para as éter-aminas, utilizadas para aumentar a eficiência do processo de flotação catiônica reversa do minério de ferro. Estudou-se um método de separação físico-química utilizando TANFLOC como floculante. As águas de rejeito contêm, em sua maior parte, amina e sílica, e o objetivo desse método era separar a sílica do rejeito. A separação físico-química, porém, não foi eficaz, visto que o processo não foi capaz de flocular somente a sílica, floculando também parte da éter-amina. Foi avaliado também o processo de adsorção e, para tanto, utilizaram-se como materiais adsorventes a serragem Angelim e bagaço de cana-de-açúcar, ambos in natura. Esses materiais foram capazes de remover aproximadamente 95 e 90\% de éter-amina, com capacidades adsortivas de 4,2 e 2,7 mg.9'1, respectivamente, utilizando massa de 1,5 g e estabelecendo tempo de equilíbrio de 30 minutos. Verificouse que a eficiência de remoção é maior em pH próximo a 10. Pelos estudos termodinâmicos foi possível concluir, para a serragem, que o processo é termodinamicamente favorável e exotérmico. Para o bagaço de cana não foi possível analisar o comportamento termodinâmico. Além disso, o processo de dessorção permitiu recuperar em torno de 80\% de éter-amina, além da possibilidade de regeneração e reutilização dos materiais adsorventes, o que mostra a viabilidade de reciclar a éter-amina pelo mecanismo de adsorção.
\end{abstract}

Palavras-chave: adsorção; floculação; éter-amina; minério de ferro; bagaço de cana; serragem.

\begin{abstract}
The present work has the objective of investigating the possible recycling route for ether-amines, used for improving the efficiency of the process of iron ore's reverse flotation. A physical-chemical separation method has been studied using TANFLOC as flocculant. The wastewater contains, mainly, amine and silica, and the objective of this method was to separate the silica from the waste by flocculation. However, this method was not effective, as flocculation was not able to flocculate only silica, but also part of the ether-amine. Furthermore, the process of adsorption was assessed, and for this it was used as materials adsorbents Angelim's sawdust and sugar cane bagasse, both in natura, with which it was possible to remove approximately 95 and $90 \%$ of ether-amines, with adsorptive capacity of 4,2 and $2,7 \mathrm{mg} \cdot \mathrm{g}^{-1}$, respectively, by using a mass of $1.5 \mathrm{~g}$ and a settling time of 30 minutes. It was verified that the removal efficiency is greater at a $\mathrm{pH}$ around 10. Thermodynamic studies were carried out and they were able to state, for sawdust, that this process is thermodynamically favorable and exothermic. In the case of sugar cane bagasse, it was not possible to analyze its thermodynamic behavior. In addition, the use of desorption revealed the possibility of regaining around $80 \%$ of the etheramines. This proved that it is possible to recycle ether-amines by the adsorption mechanism.
\end{abstract}

Keywords: adsorption; flocculation; ether-amine; iron ore; sugar cane bagasse: sawdust.

\section{INTRODUÇÃO}

Para separar o óxido de ferro, material de interesse econômico, da sílica, é utilizado o processo de flotação catiônica reversa. A seletividade do processo de flotação baseia-se nas diferentes características de superfície dos minerais, que podem apresentar distintos graus de hidrofobicidade. Partículas mais hidrofóbicas são menos ávidas por água, permitindo sua adesão à superfície das bolhas de ar. Da mesma forma ocorre a hidrofilicidade, afinidade pela água, em que as partículas hidrofílicas

permanecem na solução aquosa e são precipitadas. As éter-aminas são coletores catiônicos que permitem flotar o quartzo e separá-lo do óxido de ferro (ARAUJO, 2007).

Os compostos de éter-aminas, utilizadas na flotação do minério de ferro, são surfactantes que possuem longa cadeia hidrofóbica e o grupo amino, hidrofílico. O grupo amino liga-se à superfície do quartzo, enquanto a cadeia carbônica, hidrofóbica, se liga à por superfície da bolha de ar, permitindo a separação (CHAVES, 2001). Em solução, os 
coletores têm sua porção polar ionizada segundo a Equação 1. Na faixa de $\mathrm{pH} 9,5$ a 10,5, as éter-aminas encontram-se em equilíbrio nas suas formas iônicas e moleculares, o que favorece a adsorção pelo quartzo, e nas formas moleculares, o que permite a adsorção pelo ar.

$\mathrm{RNH}_{2(a q .)}+\mathrm{H}_{2} \mathrm{O}_{(a q .)} \Leftrightarrow \mathrm{RNH}_{3(a q .)}^{+}+\mathrm{OH}_{(a q .)}^{-}$

Muitas aminas possuem efeitos nocivos para a saúde, podendo causar irritações na pele, nos olhos, nas membranas mucosas e nas vias respiratórias. Além disso, podem diminuir a capacidade de autodepuração dos rios ao reduzir a taxa de absorção de oxigênio (CHAVES, 2001; SILVA, 2009).

Estudos realizados por Silva (2009) mostraram que o flotado líquido possui $45 \%$ da éter-amina utilizada, com concentração variando entre 5 e $45 \mathrm{mg} . \mathrm{L}^{-1}$. Como existe quantidade expressiva desse reagente no flotado líquido, que é descartado nas barragens de rejeito, há interesse em estudar uma maneira de reciclar as éter-aminas a fim de diminuir os custos de seu consumo e o impacto ambiental.

Uma das dificuldades da reutilização de águas contendo éter-aminas dos rejeitos de flotação de minério de ferro é a presença de sílica fina, que inviabiliza o processo (BATISTELI, 2007).

Uma substância que vem sendo utilizada na floculação química, seja no tratamento de efluentes ou de água, é o TANFLOC, um polímero orgânico, biodegradável e catiônico de origem vegetal que possui baixo peso molecular.

A adsorção é um processo de separação em que ocorre a adesão de determinado soluto (elemento ou substância) à interface de um sólido. Os adsorventes são materiais porosos, e a retenção ocorre por vários fatores, como forma do soluto, diferença de peso molecular, interações químicas e polaridade (GOMES, 2010; GUSMÃO, 2011).

Muitos adsorventes de baixo custo, como resíduos industriais, agroindustriais, minerais e substâncias naturais, entre outros, estão sendo estudados como materiais capazes de substituir o uso do carvão ativado (CRINI, 2006). Entre os resíduos mais utilizados se encontram o bagaço de cana e a serragem de madeira, que são ricos em biomassa lignocelulósica e hidroxila e constituídos basicamente de celulose, hemicelulose e lignina, nas proporções de, aproximadamente, 40-50, 27 e 23\%, respectivamente (GUSMÃO, 2011; KLOCK et al., 2005).

De acordo com a Companhia Nacional de Abastecimento (CONAB, 2015), em 2014/2015 a produção nacional de cana-de-açúcar foi de 642,1 milhões de toneladas. Segundo Silva, Gomes e Alsina (2007) apud Almeida (2015), 27\% dessa massa representa a quantidade de resíduo de bagaço de cana após o processo de produção das usinas de açúcar e álcool. A indústria brasileira, segundo Albertini et al. (2007), gera em torno de 22,5 milhões de toneladas de resíduos de madeira.

Estudos de adsorção em zeólitas e carvão ativado realizados por Teodoro (2004) indicaram que é possível adsorver a amina em 95\% utilizando as zeólitas (capacidade adsortiva $-\mathrm{qe}=81 \mathrm{mg} \cdot \mathrm{g}^{-1}$ ) como adsorvente e em $100 \%$ empregando carvão ativado $\left(\mathrm{qe}=65 \mathrm{mg} \cdot \mathrm{g}^{-1}\right)$, em pHs 10 e 3. Magriotis et al. (2010) investigaram a adsorção de éter-amina em caulinita branco $\left(\mathrm{qe}=33 \mathrm{mg} \cdot \mathrm{g}^{-1}\right)$, rosa $\left(\mathrm{qe}=34 \mathrm{mg} \cdot \mathrm{g}^{-1}\right) \mathrm{e}$ amarelo (qe=23 mg.g ${ }^{-1}$ ), obtendo 77, 80 e 69\% de remoção, respectivamente, para pH 10. Já Gusmão et al. (2014), que estudaram o processo de adsorção de éter-amina em bagaços de cana quimicamente modificados com anidrido succínico ( $\mathrm{qe}=869,56 \mathrm{mg} \cdot \mathrm{g}^{-1}$ ) e dianidrido do EDTA (qe=1.203,45 mg.g ${ }^{-1}$ ), obtiveram 63 e 65\% de remoção, respectivamente, também para $\mathrm{pH} 10$.

O presente trabalho teve por objetivo estudar a recuperação de éter-amina presente no rejeito de flotação do minério de ferro. Verificou-se a viabilidade da separação físico-química da sílica da éter-amina utilizando o TANFLOC e buscou-se estudar novos adsorventes para a recuperação das éter-aminas por adsorção/dessorção, com o intuito de identificar a melhor rota de reciclagem desse coletor.

\section{MATERIAIS E MÉTODOS}

\section{Quantificação de éter-amina}

A quantificação da éter-amina foi realizada pelo método Orange II, validado no Laboratório de Resíduos Sólidos Industriais e Efluentes Líquidos do Departamento de Química da Universidade Federal de Ouro Preto (DEQUI/UFOP), de acordo com as especificações do Instituto Nacional de Metrologia, Qualidade e Tecnologia (INMETRO) de 2003 (apud CAVALLIERI, 2011). As leituras de absorbância foram realizadas em um espectrofotômetro Biospectro SP-220, com comprimento de onda de $485 \mathrm{~nm}$ e cubeta de $10 \mathrm{~mm}$.

\section{Estudos de separação físico-química}

Foram preparadas soluções aquosas, nos pHs de 7 e 10, contendo uma solução de sílica $40 \mathrm{mg} . \mathrm{L}^{-1}$ com granulometria -325+400 mesh $(-44+37 \mu \mathrm{m})$ e o passante de -400 mesh $(-37 \mu \mathrm{m})$ e éter-amina a $40 \mathrm{mg} . \mathrm{L}^{-1}$. Adicionou-se $0,1 \mathrm{~g}$ do floculante TANFLOC a $50 \mathrm{~mL}$ da solução, ajustou-se o pH e agitou-se por 20 minutos; em seguida, mediu-se a turbidez e deixou-se a solução em repouso por 4 horas para flocular. Posteriormente, filtrou-se a mistura, mediu-se novamente a turbidez e quantificaram-se os teores de amina em cada solução.

\section{Teste de adsorção}

\section{Caracterização dos materiais adsorventes}

O bagaço de cana, obtido em um comércio da cidade de Ouro Preto (MG), e a serragem Angelim, obtida na serraria da UFOP, foram lavados por três vezes com água da torneira e secos em estufa a $50^{\circ} \mathrm{C}$ até a completa secagem. Em seguida, os materiais foram moídos em um 
moinho de facas e o pó obtido passou novamente por cinco lavagens consecutivas, com água destilada a $70^{\circ} \mathrm{C}$, a fim de remover os resíduos. Posteriormente, o material foi seco em estufa a $60^{\circ} \mathrm{C}$, até a completa secagem, e a granulometria foi ajustada por peneiras série Tyler, com aberturas de 32, 48, 60, 100 e 150 mesh (\#).

Após o pré-tratamento, os materiais foram caracterizados por meio do infravermelho com transformada de Fourier (IVTF), medidas de área superficial específica e ponto de carga zero $\left(\mathrm{pH}_{\mathrm{PCZ}}\right)$. Para as análises de IVTF, prepararam-se pastilhas com $1 \mathrm{mg}$ da amostra misturada com $100 \mathrm{mg}$ de $\mathrm{KBr}$, as quais foram lidas em espectrômetro de IVTF, modelo MB3000, ABB Bomem. Os espectros foram obtidos na faixa de $4.000-400 \mathrm{~cm}^{-1}$. As medidas de área superficial específica foram baseadas no método de Brunauer-Emmett-Teller (BET), sendo utilizado o equipamento NOVA 1000. Para a determinação do $\mathrm{pH}_{\mathrm{PCZ}}$, empregou-se a metodologia desenvolvida por Valdés et al. (2002) e Tonucci (2014), em que uma solução de nitrato de sódio em diferentes valores de $\mathrm{pH}$ é colocada em agitação com o material, variando a sua massa. Ao término do processo, mediu-se o $\mathrm{pH}$ final das amostras. Os resultados obtidos foram utilizados na construção de um gráfico $\mathrm{pH}$ versus porcentagem em massa do adsorvente, e a determinação do PCZ foi feita definindo-se o ponto de convergência das três curvas.

\section{Ensaios de adsorção}

As soluções foram preparadas utilizando-se a éter-monoamina PA14F-ED, cedida por uma mineradora A de MG. Para todos os ensaios, a solução de éter-amina foi quantificada pelo método Orange II antes e depois da adsorção. Todos os ensaios de adsorção foram realizados em triplicata e em temperatura controlada de $25^{\circ} \mathrm{C}$, exceto os ensaios de isotermas de adsorção, nos quais se analisou o comportamento da adsorção em $25,35,45$ e $55^{\circ} \mathrm{C}$.

A amostra foi preparada na forma de solução aquosa de éter-amina de $50 \mathrm{mg} . \mathrm{L}^{-1}$. Em seguida, $50 \mathrm{~mL}$ da solução foi vertida para diferentes erlenmeyers de $250 \mathrm{~mL}$ contendo o material adsorvente. Posteriormente, os erlenmeyers foram colocados em uma incubadora refrigerada com agitação TE-424 da TECNAL. Os tempos de agitação variaram, conforme os ensaios, de 1 a 120 min. Após a agitação, as amostras foram separadas por centrifugação a $3.500 \mathrm{rpm}$ utilizando uma centrífuga Excelsa Baby II, modelo 206, por 7 min. O sobrenadante foi quantificado pelo método do Orange II.

A taxa de remoção $(\mathrm{R})$ e a capacidade adsortiva $\left(\mathrm{q}_{\mathrm{e}}\right)$ foram calculadas a partir das Equações 2 e 3, respectivamente:

$$
\begin{aligned}
& R(\%)=\frac{\left(C_{i}-C_{f}\right) \times 100}{C_{i}} \\
& q_{e}=\frac{\left(C_{i}-C_{f}\right) x V}{m}
\end{aligned}
$$

Em que:
$\mathrm{C}_{\mathrm{i}}=$ concentração inicial;

$\mathrm{C}_{\mathrm{f}}=$ concentração final;

$\mathrm{V}=$ volume;

$\mathrm{m}=$ massa.

Dessa forma, foram estudados os seguintes parâmetros: tempo, $\mathrm{pH}$, concentração de éter-amina, granulometria e massa de adsorvente. Para a determinação da massa, manteve-se o tempo constante em 120 min. e o pH em 9,6, variando a massa de 0,25 a 2,5 g. Para os testes de granulometria, a massa permaneceu constante em 1,5 g, o tempo em 120 min. e o $\mathrm{pH}$ em 9,6, variando a granulometria de 32 a 150 mesh (\#). Para o $\mathrm{pH}$, os procedimentos foram análogos, variando-se o $\mathrm{pH}$ de 3 a 11 e mantendo-se constante a massa em 1,5g e o tempo em 120 min.

Para os estudos cinéticos, manteve-se a massa constante em 1,5 g, o pH em 9,6, variando-se as concentrações de éter-amina em 10, 20, 40, 50, 60 e 75 mg.L L $^{-1}$, e o tempo em 1, 5, 15, 30, 45, 60, 75, 90, 105 e 120 min. Para os estudos cinéticos do bagaço de cana e os ensaios de isoterma, foi necessário realizar a filtração como método de separação da mistura, adaptando-se um "saquinho de amostragem" de polietileno de baixa densidade (PEBD) como filtro. Nos experimentos para obtenção das isotermas, fez-se o controle do $\mathrm{pH}$ antes e depois da adsorção a fim de observar se ocorria troca iônica entre a solução e os adsorventes. $\mathrm{O}$ tempo de contato foi estabelecido em $30 \mathrm{~min}$. e o $\mathrm{pH}$ inicial foi próximo a 10.

\section{Dessorção}

Estudou-se a possibilidade de recuperar a éter-amina pelo processo dessortivo, utilizando-se o material (adsorvente+éter-amina) previamente seco e uma solução de ácido acético 4 mol.L-1 ${ }^{-1}$ Os ensaios de dessorção foram realizados em temperatura controlada a $25^{\circ} \mathrm{C}$ e em tempo de agitação de 2 horas.

Após a adsorção, o sólido foi lavado por cinco vezes consecutivas com água destilada, transferido para um erlenmeyer de $250 \mathrm{~mL}$ e levado para secar em estufa a $60^{\circ} \mathrm{C}$, por 12 horas. Em seguida, após esfriar, adicionaram-se $50 \mathrm{~mL}$ de ácido acético 4 mol.L-1 e seguiu-se o procedimento de forma análoga ao da adsorção.

Pela Equação 4, é possível determinar a porcentagem de éter-amina recuperada na dessorção.

$E(\%)=\frac{C_{f-d e s}}{C_{i-a d s}-C_{f-a d s}} x 100$

Em que $\mathrm{C}_{\text {i-ads }}$ é a concentração inicial de éter-amina antes da adsorção; $\mathrm{C}_{\mathrm{f} \text {-ads }}$, a concentração em equilíbrio após a adsorção; e $\mathrm{C}_{\mathrm{f} \text {-des }}$, a concentração final após a dessorção.

Estudos utilizando o efluente real de uma mineradora 
A fim de estudar o comportamento do processo de adsorção utilizando o efluente real de uma mineradora (matriz mais complexa, contendo, além da éter-amina, sílica, ferro, amido etc.), realizou-se o processo análogo adsorção/dessorção descrito anteriormente. Foram utilizados dois resíduos: rejeito do espessador de uma grande mineradora do país (mineradora B) e rejeito da coluna de finos da mineradora A.

$O$ rejeito da coluna de finos da mineradora A se encontrava congelado em laboratório havia cinco anos. O teor das aminas presentes nesse resíduo estava praticamente ausente. Isso ocorreu por algum problema de conservação, por exemplo, falta de energia elétrica, com descongelamento da amostra. Portanto, foi feita reposição de aminas, com adição de 0,025 g de monoamina em $500 \mathrm{~mL}$ do resíduo. Essa quantidade representa o teor de aminas no rejeito recente.

\section{RESULTADOS E DISCUSSÃO}

\section{Separação físico-química}

A Tabela 1 apresenta os resultados para a solução de éter-amina $40 \mathrm{mg} \cdot \mathrm{L}^{-1}$ e para a solução de sílica com éter-amina $40 \mathrm{mg} \cdot \mathrm{L}^{-1}$. Observa-se que ocorreu eficiente floculação nos dois pHs devido à diferença entre turbidez inicial e final.

Segundo Batisteli (2007), em pH próximo a 10 a superfície do quartzo é altamente negativa. Já para o TANFLOC, em $\mathrm{pH}$ próximo a 7, faixa em que esse floculante atua de forma mais eficaz, a presença de cargas positivas é predominante, de acordo com TANAC (2013) e Roselet et al. (2016). Logo, a floculação é favorável tanto em pH 7 quanto em $\mathrm{pH} 10$, pois, à medida que diminui as cargas positivas do TANFLOC, aumenta as cargas negativas da sílica.

A éter-amina, quando hidrolisada em $\mathrm{pH}$ próximo a 10 , tem sua forma iônica em equilíbrio com sua forma molecular, portanto sua

Tabela 1 - Teste de separação de amina da sílica: medida de turbidez e teor de éter-amina.

\begin{tabular}{l|c|c|c|c|c} 
Amostra & $\mathrm{pH}$ & $\begin{array}{c}\text { Concentra- } \\
\text { ção inicial da } \\
\text { éter-amina } \\
\text { (mg.L-1) }\end{array}$ & $\begin{array}{c}\text { Turbidez } \\
\text { inicial } \\
\text { (NTU) }\end{array}$ & $\begin{array}{c}\text { Turbidez } \\
\text { final } \\
\text { (NTU) }\end{array}$ & $\begin{array}{c}\text { Concentra- } \\
\text { ção final da } \\
\text { éter-amina } \\
\text { (mg.L-1) }\end{array}$ \\
\hline $\begin{array}{l}\text { Solução de } \\
\text { éter-amina* }\end{array}$ & 7,00 & 40,61 & 37,4 & 3,78 & 25,61 \\
\hline $\begin{array}{l}\text { Solução de } \\
\text { éter-amina* }\end{array}$ & 10,03 & 40,61 & 283 & 7,53 & 2,59 \\
\hline $\begin{array}{l}\text { Solução de } \\
\text { sílica com } \\
\text { éter-amina** }\end{array}$ & 7,01 & 39,87 & 164 & 34,2 & 23,43 \\
\hline $\begin{array}{l}\text { Solução de } \\
\text { sílica com } \\
\text { éter-amina** }\end{array}$ & 10,03 & 39,87 & 288 & 6,57 & 1,01 \\
\hline
\end{tabular}

*solução de éter-amina (4O mg. $\left.\mathrm{L}^{-1}\right)$; **solução de sílica (4O mg. $\left.\mathrm{L}^{-1}\right)$ com éteramina (40 mg. $\left.L^{-1}\right)$. afinidade pela superfície negativa da sílica é maior. Acredita-se que, nesse $\mathrm{pH}$, a éter-amina interage de forma efetiva com a sílica, que, em contrapartida, interage com a superfície positiva do TANFLOC, o que faz com que a éter-amina flocule junto com a sílica.

Por meio dos resultados apresentados na Tabela 1, observa-se que o TANFLOC não é capaz de flocular somente a sílica. A éter-amina, no pH 10, que é o pH da flotação, é floculada junto com a sílica; já no pH 7 o efeito é menos pronunciado, mas ainda ocorre floculação de cerca de $50 \%$ da éter-amina.

\section{Testes de adsorção}

\section{Caracterização dos materiais}

A espectrometria na região do infravermelho é utilizada para identificar os principais grupos funcionais de uma amostra. A Figura 1 apresenta os espectros de infravermelho para o bagaço de cana e para a serragem Angelim.

A Tabela 2 apresenta os resultados das análises de área superficial e porosidade para o bagaço de cana e a serragem.

Tanto a serragem Angelim quanto o bagaço de cana possuem estrutura rica em mesoporos - visto que o diâmetro médio é maior que $20 \AA$ - e baixa área superficial específica, o que determina baixa

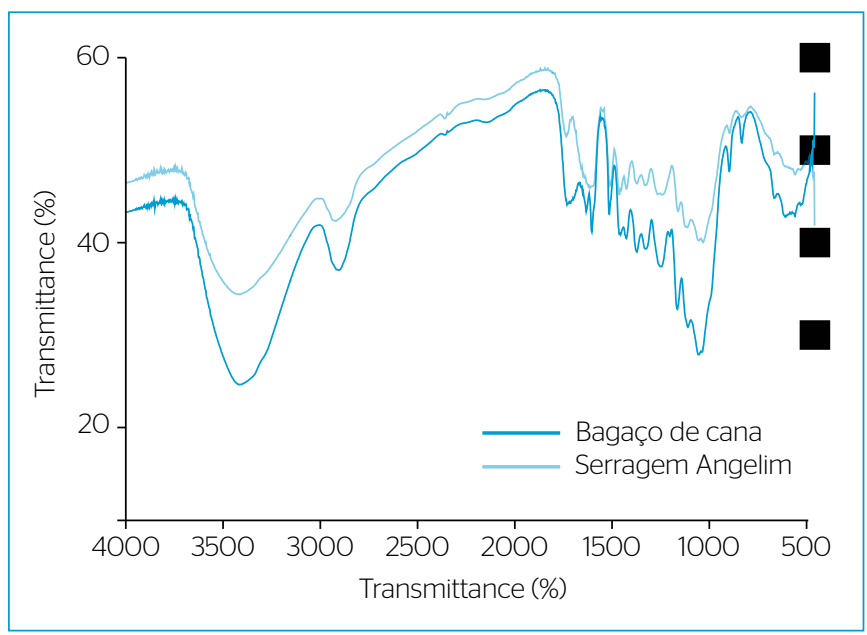

Figura 1 - Espectros de infravermelho para a serragem e o bagaço de cana.

Tabela 2 - Valores de área superficial e porosidade para o bagaço de cana e a serragem.

\begin{tabular}{l|c|c|c} 
Material & $\begin{array}{c}\text { Superfície especi- } \\
\text { fica BET }\left(\mathrm{m}^{2} \cdot \mathrm{g}^{-1}\right)\end{array}$ & $\begin{array}{c}\text { Volume total de } \\
\text { poros }\left(\mathrm{cm}^{3} \cdot \mathrm{g}^{-1}\right)\end{array}$ & $\begin{array}{c}\text { Diâmetro médio } \\
\text { dos poros }(\AA \AA)\end{array}$ \\
$\begin{array}{l}\text { Serragem } \\
\text { Angelim }\end{array}$ & 1,59 & 0,0024 & 30,1 \\
\hline $\begin{array}{l}\text { Bagaço } \\
\text { de cana }\end{array}$ & 1,65 & 0,00211 & 25,7 \\
\hline
\end{tabular}

BET: Brunauer-Emmett-Teller. 
capacidade adsortiva, já que o acesso aos sítios internos de adsorção é limitado (MONTEIRO, 2010).

O PCZ é determinado pelo ponto de convergência das três curvas presentes na Figura 2, sendo os valores para a serragem Angelim e para o bagaço de cana, respectivamente, de $4,7 \pm 0,3$ e 3,3 $\pm 0,3$. Os materiais adsorventes utilizados neste estudo têm caráter ácido e, como a solução de éter-amina possui pH próximo a 9,5, os materiais apresentam valores de $\mathrm{pH}$ menores que o adsorvato e, portanto, carga superficial negativa em suas superfícies (GUSMÃO, 2011).

\section{Ensaios de adsorção}

A partir de 1,5 g de material adsorvente, a taxa de remoção de éter-amina não sofre alterações significativas, tanto para o bagaço de cana quanto para a serragem Angelim. Para os ensaios de adsorção, utilizaram-se serragem Angelim com granulometria $<-32$ mesh $(<-500 \mu \mathrm{m})$ e bagaço de cana com granulometria $<60$ mesh $(<250 \mu \mathrm{m})$, sendo o $\mathrm{pH}$ ideal de adsorção próximo a 10 .

\section{Cinética de adsorção}

O tempo ideal em que o equilíbrio é garantido para os dois materiais em todas as faixas de concentração é de 30 minutos. A fim de investigar o mecanismo de adsorção, utilizaram-se os modelos cinéticos de pseudoprimeira ordem (PsPO) e pseudossegunda ordem (PsSO), segundo as equações linearizadas 5 e 6, respectivamente (GUSMÃO et al., 2014).

$\ln \left(q_{e}-q_{t}\right)=\ln q_{e}-k_{1} t$ $\frac{1}{\left(q_{e}-q_{t}\right)}=\frac{1}{q_{e}}+k_{2} t$

Em que:

$\mathrm{q}_{e}$ e $\mathrm{q}_{\mathrm{t}}\left(\mathrm{mg} \cdot \mathrm{g}^{-1}\right)$ = capacidades de adsorção no equilíbrio e no tempo, respectivamente;

$\mathrm{k}_{1}$ e $\mathrm{k}_{2}=$ constantes de velocidade de adsorção.

A Figura 3 ilustra o comportamento cinético desses modelos, para uma solução de éter-amina de aproximadamente $40 \mathrm{mg} . \mathrm{L}^{-1}$, para serragem Angelim e bagaço de cana.

A Tabela 3 apresenta os parâmetros cinéticos obtidos, a partir dos modelos estudados, para a serragem Angelim e o bagaço de cana.

De acordo com os parâmetros calculados, o PsSO é o que melhor se ajusta aos dados obtidos experimentalmente, visto que seu coeficiente de correlação linear é mais próximo a 1 unidade (superior a 0,99), tanto para a serragem Angelim quanto para o bagaço de cana. É possível observar, também, que o valor de $q_{e, c a ́ l c}$ para o PsPO está mais próximo aos valores de $\mathrm{q}_{\mathrm{e}}$ encontrados experimentalmente, o que constitui mais uma evidência de que o modelo cinético PsSO é o que melhor se ajusta aos dados experimentais.

\section{Isotermas de adsorção}

Por meio da Figura 4, percebe-se que nenhum dos modelos se ajustou de forma satisfatória aos dados experimentais. Para a serragem, o sistema a $25^{\circ} \mathrm{C}$ ajustou-se ao modelo de Langmuir, que prediz que a adsorção ocorre em monocamada, e para o bagaço de cana não houve ajustes significativos.

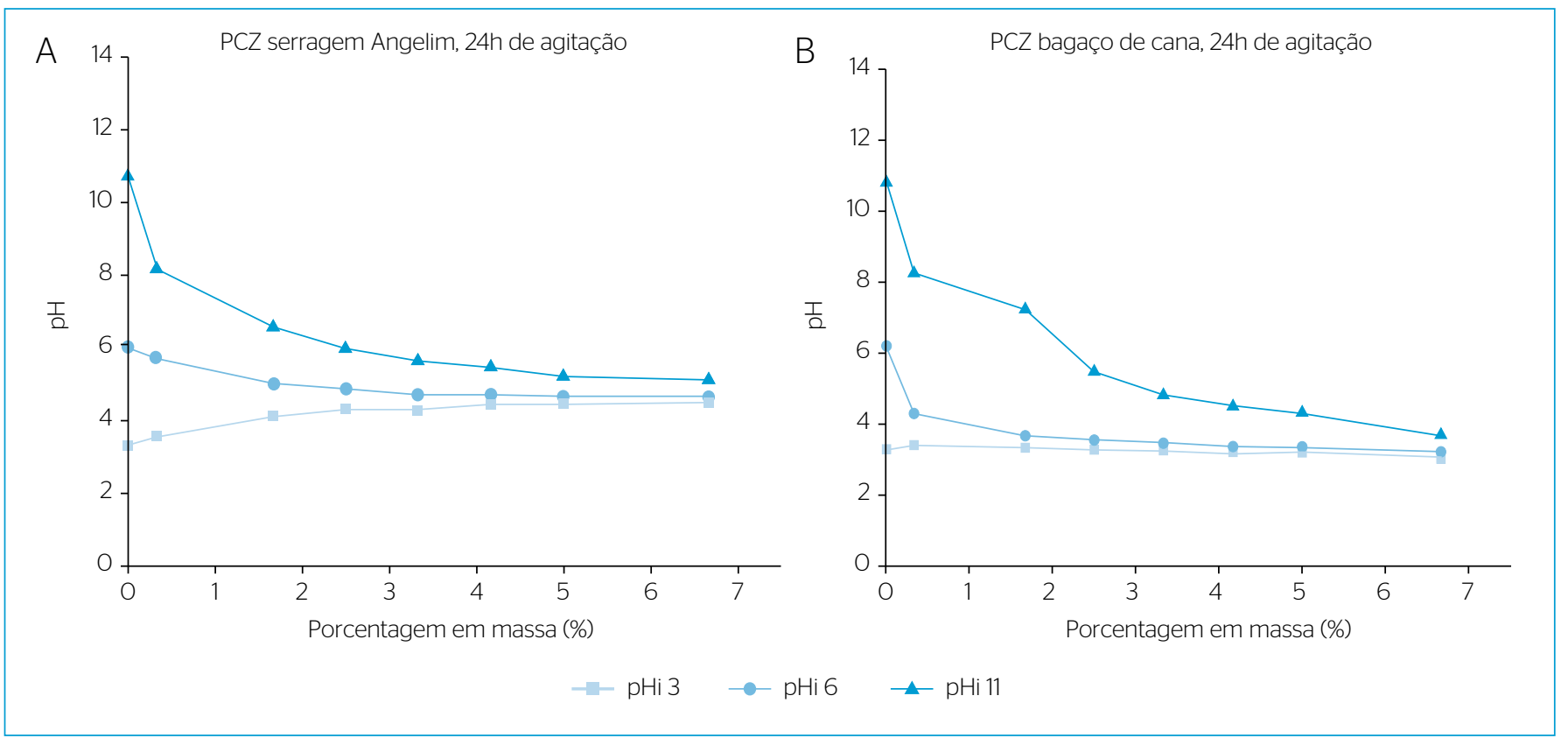

Figura 2 - Curva de pH versus porcentagem em massa de adsorvente na determinação do ponto de carga zero: (A) serragem Angelim; (b) bagaço de cana. 
Os parâmetros calculados a partir dos modelos de Langmuir, Freundlich e Temkin são apresentados na Tabela 4, bem como suas respectivas equações linearizadas.

Para a determinação dos parâmetros termodinâmicos, utilizaram-se as Equações 7 e 8. Para o cálculo de $\Delta \mathrm{H}^{\circ}$ e $\Delta \mathrm{S}^{\circ}$, empregou-se o gráfico de Van’t Hoff, apresentado na Figura 5 e na Equação 9 (WANG \& LI, 2013).

$G^{\circ}=H^{\circ}-T S^{\circ}=R T \ln k_{c}$

$K_{c}=\frac{C_{s}}{C_{e}}$

$\operatorname{In} k_{c}=\frac{H^{\circ}}{R T}+\frac{S^{\circ}}{R}$

Em que:

$\Delta \mathrm{G}^{\mathrm{o}}=$ variação da energia livre de Gibbs;

$\mathrm{k}_{\mathrm{c}}=$ constante de equilíbrio termodinâmico;

$\mathrm{T}$ = temperatura absoluta em Kelvin;
$\mathrm{R}=$ constante dos gases ideais;

$\mathrm{C}_{\mathrm{s}}=$ concentração de equilíbrio sobre o adsorvente;

$\mathrm{C}_{\mathrm{e}}=$ concentração de equilíbrio do corante em solução;

$\Delta \mathrm{H}^{\mathrm{o}}=$ entalpia;

$\Delta S^{\circ}=$ entropia .

Não foi possível calcular os parâmetros termodinâmicos para o bagaço de cana, pois os dados obtidos para esse material não se ajustaram de forma satisfatória.

Pressupõe-se que dois fatores podem ter influenciado nos resultados das isotermas de adsorção:

- a falta de controle da umidade nos materiais adsorventes;

- os resultados insatisfatórios dos testes de adsorção, no caso de amostras com concentrações iniciais abaixo de $40 \mathrm{mg} . \mathrm{L}^{-1}$. Nessa situação, a absorbância, após tais testes, era muito baixa já na primeira extração $(\approx 0,05)$. Tal valor corresponde ao limite de detecção do equipamento.

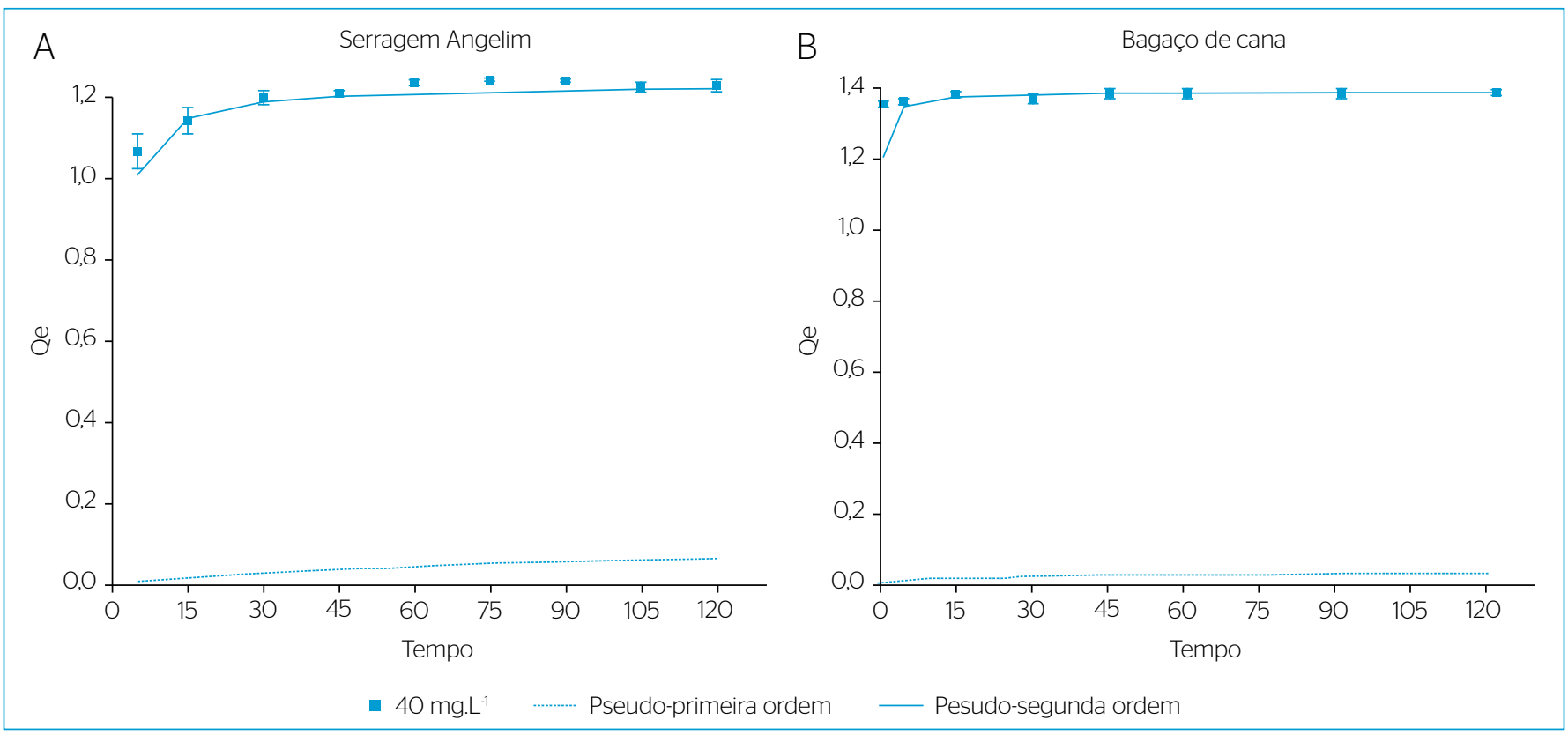

Figura 3 - Modelo cinético não linear: (A) serragem Angelim; (B) bagaço de cana.

Tabela 3 - Parâmetros obtidos a partir dos modelos cinéticos pseudoprimeira ordem (PSPO) e pseudossegunda ordem (PsSO).

\begin{tabular}{|c|c|c|c|c|}
\hline & \multicolumn{2}{|c|}{ Serragem Angelim } & \multicolumn{2}{|c|}{ Bagaço de cana } \\
\hline Parâmetros & PsPO & PsSO & $\mathrm{PsPO}$ & PsSO \\
\hline $\mathrm{Q}_{\text {eexp }}\left(m g \cdot g^{-1}\right)$ & 1,235 & - & 1,388 & - \\
\hline $\mathrm{Q}_{\mathrm{e}, \text { calc }}\left(\mathrm{mg} \cdot \mathrm{g}^{-1}\right)$ & 0,076 & 1,23 & 0,028 & 1,39 \\
\hline$K^{*}$ & 0,014 & 0,732 & 0,039 & 4,75 \\
\hline $\mathrm{R}^{2}$ & 0,860 & 0,999 & 0,934 & 0,999 \\
\hline
\end{tabular}

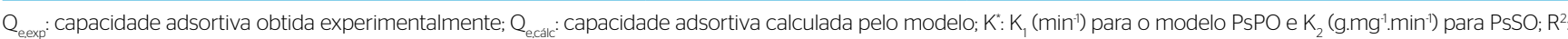
coeficiente de correlação linear. 
Esses fatores podem ter influenciado na constante de equilíbrio do sistema, não favorecendo, assim, o ajuste dos dados para o bagaço.

Já para a serragem Angelim, o coeficiente angular e linear do gráfico de Van't Hoff permitiu determinar as variações de entalpia e entropia, que são apresentadas na Tabela 5.

Os parâmetros termodinâmicos calculados indicam que o processo de adsorção é espontâneo e favorável. Para a serragem Angelim, além de espontâneo, ele é exotérmico e entropicamente organizado, visto que os valores de $\Delta \mathrm{G}^{\circ}, \Delta \mathrm{H}^{\circ} \mathrm{e} \Delta \mathrm{S}^{\circ}$ são negativos. A variação de entalpia classifica a adsorção como fisissorção ou quimissorção, já que, de acordo com Dotto et al. (2011) e Tonucci (2014), valores de entalpia de adsorção entre -40 e $-800 \mathrm{~kJ} \cdot \mathrm{mol}^{-1}$ são característicos de adsorção química. Para este estudo, o processo adsortivo da serragem é classificado como adsorção física. Além disso, o fato de o valor de $\Delta \mathrm{H}^{\circ}$ ser negativo indica que o processo é exotérmico e, portanto, a adsorção é favorecida em baixas temperaturas, como se pode confirmar pelo aumento do $\Delta \mathrm{G}^{\mathrm{o}}$ à medida que aumenta a temperatura, para a serragem. Para o bagaço de cana os ajustes não foram satisfatórios, apesar de suas características, como grupos funcionais e estrutura molecular, indicarem que o processo é semelhante. Sugere-se que o mecanismo envolvido nesse processo é o da troca iônica, em que o adsorvato troca íons com o material adsorvente. A evidência ocorre tanto pela baixa energia liberada nas adsorções quanto pela diminuição do $\mathrm{pH}$, o que indica doação de íons $\mathrm{H}^{+}$para a solução.
Tabela 4 - Parâmetros obtidos a partir dos modelos de isoterma a $25^{\circ} \mathrm{C}$.

\begin{tabular}{c|c|c}
\multicolumn{4}{c}{ Langmuir: $\frac{C_{e}}{q_{e}}=\frac{1}{b q_{m}}+\frac{C_{e}}{q_{m}}$} \\
\hline Parâmetros & Serragem & Bagaço \\
\hline $\mathrm{q}_{\mathrm{m}}^{*}$ & 4,19 & 2,74 \\
\hline $\mathrm{b}^{* *}$ & 0,199 & 0,450 \\
\hline $\mathrm{R}^{2}$ & 0,988 & 0,749 \\
\hline $\mathrm{R}_{\mathrm{L}}$ & 0,173 & 0,082 \\
\hline $\mathrm{DMR}(\%)$ & 4,62 & 36,4
\end{tabular}

$C_{e}$ : concentração de equilíbrio ( $\left.m g . L^{-1}\right) ; q_{e}$ : quantidade adsorvida (mg.g $\left.g^{-1}\right)$; $\mathrm{q}_{\mathrm{m}}$ : quantidade máxima que pode ser adsorvida $\left(\mathrm{mg}^{\mathrm{g}} \mathrm{g}^{-1}\right)$; b: constante de Langmuir; *mg.g." ** L. mg'; DMR: desvio médio relativo.

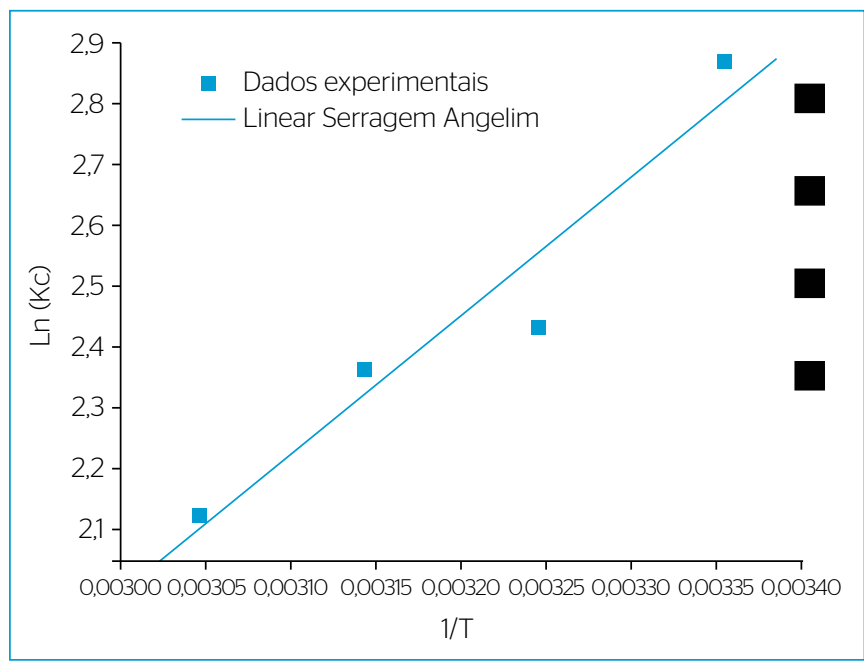

Figura 5 - Gráfico de Van’t Hoff para a serragem Angelim.

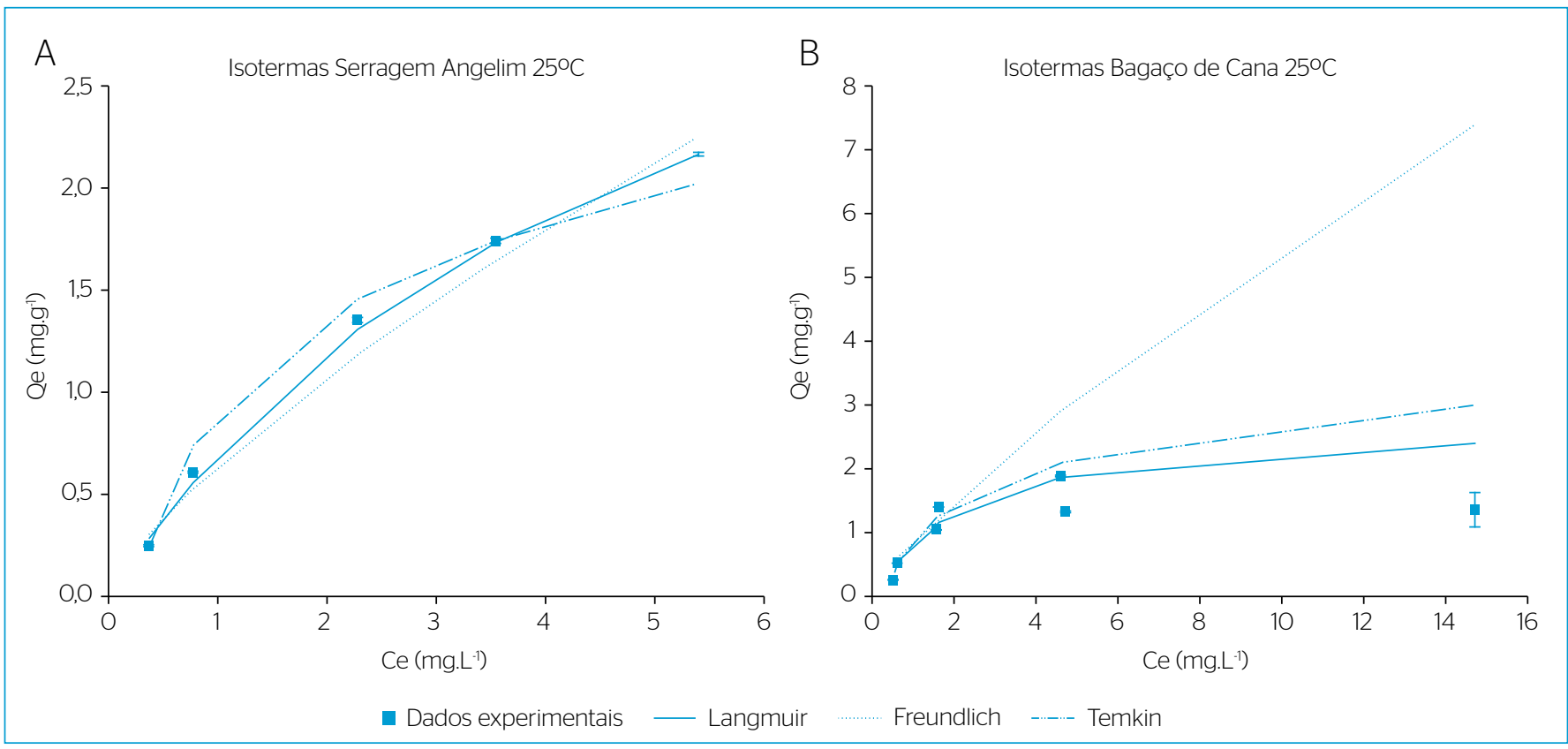

Figura 4 - Modelos isotérmicos: (A) serragem Angelim; (B) bagaço de cana. 


\section{Ensaios de dessorção}

O ácido acético é capaz de recuperar em torno de $80 \%$ da éter-amina para os dois materiais estudados. A porcentagem de dessorção varia de acordo com o pH em que foi feita a adsorção. Em amostras adsorvidas em $\mathrm{pH}$ abaixo de 6 ou acima de 10, há menor porcentagem de recuperação da éter-amina.

A possibilidade de recuperar a éter-amina utilizando ácidos como efluentes/agentes de dessorção reforça a probabilidade de o mecanismo envolvido na dessorção ser de troca iônica, já que o íon hidrônio é capaz de substituir os íons aminos nos sítios de adsorção.

\section{Ensaios com efluente real}

A Tabela 6 mostra os resultados obtidos para as análises utilizando os efluentes reais de mineradoras.

As porcentagens de remoção na adsorção foram bastante significativas, com taxas de cerca de $96 \%$ para a éter-monoamina da mineradora A e $88 \%$ para a éter-amina utilizada pela empresa B. As aminas são diferentes, e o número de carbonos na cadeia, bem como o número de grupo amino (diamina com 2 e monoamina com 1), pode influenciar no processo de adsorção/dessorção devido à intensidade das interações eletrostáticas e ao tamanho da molécula.

Dada a alta capacidade dos materiais em adsorver a éter-amina de efluente real, a dessorção apresenta valores baixos, o que indica forte interação eletrostática entre o resíduo, a éter-amina e os materiais. Ainda assim, é possível recuperar parte do material. São necessários estudos de flotação com o reagente reciclado a fim de analisar a possibilidade de reúso desse material após os processos adsortivo/dessortivo.

\section{CONCLUSÃO}

Pelos resultados obtidos no presente trabalho, é possível concluir:

- para o método físico-químico de floculação utilizando TANFLOC, observou-se que não é possível separar a éter-amina do rejeito de mineração, já que até $95 \%$ da éter-amina, presente com a sílica, também é floculada, o que inviabiliza o processo;

- a serragem Angelim e o bagaço de cana mostraram-se eficientes na remoção da éter-amina utilizada na flotação do minério de ferro, com taxas aproximadas de 95 e 90\%, respectivamente. O melhor pH de adsorção é aquele próximo a 10, e o tempo necessário para que ocorra equilíbrio de adsorção é 30 minutos. Para os estudos de cinética de adsorção, o modelo PsSO ajustou-se melhor aos dados obtidos experimentalmente;

- ao aplicar os dados experimentais aos modelos de adsorção de Langmuir, Freundlich e Temkin, apenas o sistema serragem/éter-amina em $25^{\circ} \mathrm{C}$ seguiu o modelo de Langmuir (adsorção em monocamada). Os demais modelos não foram convenientemente ajustados pelas equações citadas. Outros modelos de adsorção precisam ser estudados para esses sistemas. As capacidades máximas adsortivas para a serragem Angelim e para o bagaço de cana a $25^{\circ} \mathrm{C}$ são, respectivamente, de 4,19 e 2,74 mg.g ${ }^{-1}$;

- de acordo com os parâmetros termodinâmicos, a adsorção para a serragem é espontânea e exotérmica. Para o bagaço não foi possível concluir o comportamento termodinâmico a partir dos dados obtidos;

- os estudos de dessorção mostraram que é possível recuperar até $80 \%$ da éter-amina com ácido acético 4 mol.L-1 ${ }^{-1}$ valor que pode diminuir de acordo com as condições do meio (umidade e

Tabela 5 - Parâmetros termodinâmicos para a serragem Angelim.

\begin{tabular}{|c|c|c|c|c|c|c|}
\hline Parâmetros/temperatura (K) & $\mathrm{pH}$ inicial & pH final & $\Delta \mathrm{G}^{\circ}\left(\mathrm{kJ} \cdot \mathrm{mol}^{-1}\right)$ & $\Delta \mathrm{H}^{\circ}\left(\mathrm{kJ} \cdot \mathrm{mol}^{-1}\right)$ & $\Delta \mathrm{S}^{\circ}\left(\mathrm{J} \cdot \mathrm{mol}^{-1} \cdot \mathrm{K}^{-1}\right)$ & $\mathrm{R}^{2}$ \\
\hline 298 & 10,2 & 5,78 & $-7,13$ & \multirow{4}{*}{$-19,02$} & \multirow{4}{*}{$-40,46$} & \multirow{4}{*}{0,963} \\
\hline 308 & 10,4 & 5,86 & $-6,24$ & & & \\
\hline 318 & 10,5 & 5,99 & $-6,26$ & & & \\
\hline 328 & 10,4 & 6,09 & $-5,79$ & & & \\
\hline
\end{tabular}

$\Delta G$ : variação da energia livre de Gibbs; $\Delta H^{\circ}$ : entalpia; $\Delta S^{\circ}$ : entropia; $R^{2}$ : coeficiente de correlação linear.

Tabela 6 - Análise com efluente real.

\begin{tabular}{|c|c|c|c|c|c|}
\hline Adsorvente/adsorvato & $\begin{array}{c}\mathrm{pH} \\
\text { inicial }\end{array}$ & Concentração inicial (mg. $\left.\mathrm{L}^{-1}\right)$ & Remoção na adsorção (\%) & $\begin{array}{c}\mathrm{pH} \\
\text { final }\end{array}$ & Recuperada na dessorção (\%) \\
\hline Bagaço/coluna I mineradora A & 9,95 & 49,22 & 96,31 & 5,07 & 39,96 \\
\hline $\begin{array}{l}\text { Bagaço/espessador de rejeito da } \\
\text { mineradora B }\end{array}$ & 10,35 & 791,9 & 89,77 & 7,66 & 42,16 \\
\hline
\end{tabular}


$\mathrm{pH})$. Os materiais podem ser reutilizados por mais de um ciclo no processo adsortivo, o que pode ser vantajoso economicamente. Estudos preliminares mostram que, mesmo na matriz complexa do efluente real, é possível adsorver em torno de $96 \%$ de éter-amina. As interações com o efluente real, porém, são mais fortes, já que apenas $40 \%$ do coletor foi recuperado na dessorção. Pode-se concluir, portanto, que é possível reciclar a éter-amina, utilizada na flotação do minério de ferro, por meio da adsorção/dessorção.

\section{FONTE DE FINANCIAMENTO}

UFOP, Fundação de Amparo à Pesquisa do Estado de Minas Gerais (FAPEMIG).

\section{REFERÊNCIAS}

ALBERTINI, S.; CARMO, L.F.; PADRO FILHO, L.G. (2007) Use of sawdust and pulp from cane as adsorbents of cadmium. Food Science and Technology, Campinas, v. 27, n. 1.

ALMEIDA, L.F.P. (2015) Pelletização do bagaço de cana-de-açúcar: Estudo das propriedades do produto e rendimento do processo. 84f. Dissertação (Programa de Pós-Graduação em Engenharia de Produção) - Universidade Tecnológica Federal do Paraná, Ponta Grossa.

ARAUJO, D.M. (2007) Reciclagem de resíduos da flotação de minério de ferro: Caracterização e estudos da biodegração das aminas nas barragens de rejeito. 130f. Tese (Doutorado em Ciências Químicas) - Universidade Federal de Minas Gerais, Belo Horizonte.

BATISTELI, G.M.B. (2007) Amina residual na flotação catiônica reversa de minério de ferro. 118f. Dissertação (Mestrado em Engenharia Metalúrgica e de Minas) - Universidade Federal de Minas Gerais, Belo Horizonte.

CAVALLIERI, H.C.F. (2011) Estudo da biodegradação de éteraminas utilizadas na flotação do minério de ferro. 211f. Dissertação (Mestrado em Engenharia Ambiental) - Universidade Federal de Ouro Preto, Ouro Preto.

CHAVES, L.C. (2001) Estudo de resíduos sólidos gerados na flotação de minério de ferro: Quantificação e decomposição de aminas no meio ambiente. 90f. Dissertação (Mestrado em Evolução Crustal e Recursos Naturais) - Universidade Federal de Ouro Preto, Ouro Preto.

COMPANHIA NACIONAL DE ABASTECIMENTO (CONAB). (2O15) 30 Levantamento - Safra 2015/16. Brasil: CONAB.

CRINI, G. (2006) Non-conventional low-cost adsorbents for dye removal: a review. Bioresource Technology, v.97, n.9, p.1061-1085. https://doi.org/10.1016/j.biortech.2005.05.001

DOTTO, G.L.; VIEIRA, M.L.G.; GONÇALVES, J.O.; PINTO, L.A.A. (2O11) Remoção dos corantes azul brilhante, amarelo crepúsculo e amarelo tartazina de soluções aquosas utilizando carvão ativado, terra ativada, terra diatomácea, quitina e quitosana: Estudos de equilíbrio e termodinâmica. Química Nova, v.34, n.7, p.1193-1199. http://dx.doi.org/10.1590/S0100-40422011000700017
GOMES, B.L. (2010) Adsorção dos corantes têxteis vermelho $B S B$, vermelho trifix e azul marinho CLR com resíduo da fabricação de alumina. 116f. Dissertação (Mestrado em Engenharia Ambiental) - Universidade Federal de Ouro Preto, Ouro Preto.

GUSMÃO, K.A.G. (2011) Estudo de adsorção em solução aquosa de dois corantes catiônicos e de uma éter-amina usando bagaço de cana modificado quimicamente. 107f. Dissertação (Mestrado em Engenharia Ambiental) - Universidade Federal de Ouro Preto, Ouro Preto.

GUSMÃO, K.A.G.; GURGEL, L.V.A.; MELO, T.M.S.; CARVALHO, C.F.; GIL, L.F. (2014) Adsorption studies of ether diamine onto modified sugar cane bagasses in aqueous solution. Journal of Environmental Management, v.133, p.332-342. http://dx.doi. org/10.1016/j.jenvman.2013.11.040

KLOCK, U.; MUÑIZ, G.I.B.; HERNANDEZ, A.; ANDRADE, A.S. (2005) Química da madeira.3. ed. Curitiba.

MAGRIOTIS, Z.M.; LEAL, P.V.B.; SALES, P.F.; PAPINI, R.M.; VIANA, P.R.M. (2010) Adsorption of ether amine on kaolinite: a cheap alternative for the treatment of mining effluents. Journal of Hazardous Materials, v.184, n.1-3, p.465-471. http://dx.doi.org/10.1016/j. jhazmat.2010.08.057

MONTEIRO, M.S. (2010) Mesocarpo de coco verde (Cocos nucifera) e pó de serragem de tatajuba (Bagassa Guianensis Aubl) como adsorventes em meio aquoso. 83f. Dissertação (Programa de Pós-Graduação em Química) - Universidade Federal do Maranhão, São Luís.

ROSELET, F.; BURKERT, J.; ABREU, P.C. (2016) Flocculation of Nannochloropsis oculata using a tannin-based polymer: bench scale optimization and pilot scale reproducibility. Biomass and Bioenergy, v. 87, p. 55-60. https://doi.org/10.1016/j. biombioe.2016.02.015

SILVA, F.M.F. (2009) Quantificação de éter-aminas em rejeitos da flotação de minério de ferro em função da granulumetria. 90f. Dissertação (Mestrado em Engenharia Ambiental) - Universidade Federal de Ouro Preto, Ouro Preto. 
TANAC S.A. (2013) Produto: Tratamento de águas [catálogo Tanfloc SL]. Tanac S.A. Disponível em: <http://www.tanac.com.br/ pt-br/produtos/aguas>. Acesso em: 5 ago. 2016.

TEODORO, A.L. (2004) Remoção de amina em carvão ativado e zeólita como alternativa para o tratamento de efluentes na indústria de minério de ferro. 78f. Dissertação (Mestrado em Engenharia Mineral) - Escola de Minas, Universidade Federal de Ouro Preto, Ouro Preto.

TONUCCl, M.C. (2014) Adsorção de diclofenaco, estradiol e sulfametoxazol em carvões ativados e nanotubos de carbono: estudos cinéticos e termodinâmicos. 109f. Dissertação (Programa de Pós-Graduação em Engenharia Ambiental) - Universidade Federal de Ouro Preto, Ouro Preto.

VALDÉS, H.; SÁNCHEZ-POLO, M.; RIVERA-UTRILLA, J.; ZAROT, C.A. (2002) Effect of ozone treatment on surface properties of activated carbon. Langmuir, v.18, n.6, p.2111-2116. http://dx.doi.org/10.1021/ laO10920a

WANG, L.; LI, J. (2013) Adsorption of C.I reactive red 228 dye from aqueous solutions by modified cellulose from flaxshive: Kinetics, equilibrium, and thermodynamics. Industrial Crops and Products, v.42, n.1, p.153-158. http://dx.doi.org/10.1016/j. indcrop.2012.05.031 